\title{
Erratum to: Predicting the potential distribution of the invasive Common Waxbill Estrilda astrild (Passeriformes: Estrildidae)
}

\author{
Darius Stiels • Kathrin Schidelko • Jan O. Engler • \\ Renate van den Elzen • Dennis Rödder
}

Published online: 19 August 2011

(C) Dt. Ornithologen-Gesellschaft e.V. 2011

\section{Erratum to: J Ornithol (2011) 152:769-780 \\ DOI 10.1007/s10336-011-0662-9}

An erroneous range for the LDA overlap analyses in multivariate E-space was stated in the methods section (subsection: Comparison of climatic niches). Instead of a range of 0 (no overlap) to 1 (total overlap), the parameter ranges only from 0 (no overlap) to 0.5 (total overlap). Due to random group predictions when two groups cover identical E-space, the maximum discriminance value cannot exceed 0.5. Thus, an overlap of $0.32( \pm 0.057)$ (results section, subsection: Comparison of climate niches) rather indicates a "modest" than a "low" overlap. However, general conclusions as stated in the discussion section are not altered as the climate at invasive locations still nests within the substantially larger occupied E-space of the native population.

The online version of the original article can be found under doi:10.1007/s10336-011-0662-9.

D. Stiels $(\bowtie) \cdot$ K. Schidelko - J. O. Engler · R. van den Elzen ·

\section{Rödder}

Zoological Research Museum Alexander Koenig,

Adenauerallee 160, 53113 Bonn, Germany

e-mail: d.stiels.zfmk@uni-bonn.de

J. O. Engler · D. Rödder

Biogeography Department, Trier University,

54286 Trier, Germany 